\title{
Modifikasi Perencanaan Gedung Apartemen Grand Dhika City Jatiwarna Bekasi - Tower Emerald Menggunakan Sistem Rangka Bresing Konsentris
}

\author{
Arif Rijal, Heppy Kristijanto dan Budi Suswanto \\ Departemen Teknik Sipil, Fakultas Teknik Sipil dan Perencanaan, Institut Teknologi Sepuluh Nopember (ITS) \\ e-mail: heppy@ce.its.ac.id
}

\begin{abstract}
Abstrak-Gedung Apartemen Grandhika City Jatiwarna Bekasi - Tower Emerald merupakan sebuah gedung apartemen yang terdiri dari 22 lantai yang didesain menggunakan struktur beton bertulang. Gedung ini terletak didaerah Jabodetabek dimana merupakan daerah yang rawan gempa. Dalam studi ini dilakukan perencanaan ulang dengan memodifikasi strukturnya menjadi struktur baja komposit dengan sistem rangka bresing konsentris khusus jenis inverted - V. Sistem rangka bresing konsentris khusus berfungsi sebagai penahan gaya lateral yang memiliki tingkat kekakuan yang cukup baik dibanding sistem Moment Resisting Frame (MRF) dan proses pelaksanaan dan perawatan yang mudah.Dalam penyelesaiannya, akan dilakukan analisis struktur utama yang terdiri dari balok, kolom, dan bresing yang akan dimodelkan dengan alat bantu ETABS. Telah dilakukan perhitungan modifikasi perencanaan struktur Gedung Apartemen Grand Dhika City Jatiwarna menggunakan Sistem Rangka Bresing Konsentris Khusus (SRBKK). Perhitungan struktur yang dilakukan mengacu pada SNI 1729-2015, SNI 1726-2012, SNI 1727-2013 dan PPIUG 1983. Dari analisis dan hasil perhitungan diperoleh hasil, yaitu: tebal pelat atap dan lantai $11 \mathrm{~cm}$, dimensi balok induk ada 2 macam yaitu WF500.300.11.15 dan WF450.200.9.14, dimensi kolom lantai 1-7 CFT 600.600.32.32, dimensi kolom lantai 8-14 CFT 550.550.22.22, dimensi bresing menggunakan WF 600.300.12.20, dan base plate menggunakan fixed plate dari katalog Continental Steel. Sambungan struktur utama direncanakan sebagai sambungan kaku dengan baut fub 825 Mpa. Perencanaan pondasi menggunakan tiang pancang beton pracetak diameter $60 \mathrm{~cm}$ dengan kedalaman $22 \mathrm{~m}$. Kolom pedestal direncanakan dengan ukuran $1200 \mathrm{~mm}$ x $1200 \mathrm{~mm}$ dengan tulangan utama $32 \mathrm{D} 25$ dan sloof ukuran $40 \mathrm{~cm} \times 90 \mathrm{~cm}$ dengan tulangan utama 4D20 dan tulangan geser Ø10-150.
\end{abstract}

Kata Kunci-Baja-Beton Komposit, Bresing Konsentris, Apartemen.

\section{PENDAHULUAN}

$\mathrm{W}$ ILAYAH Jakarta dan sekitarnya (Jabodetabek) merupakan daerah yang rawan gempa. Dilihat dari beberapa kejadian gempa yang menerjang Jakarta dan sekitarnya. Yang terbaru terjadi pada Rabu 19 Oktober 2016 lalu, gempa dengan kekuatan 6,5 skala Richter mengguncang pantai utara Jakarta, Banten, dan Jawa Barat. Meski gempa ini tidak menimbulkan kerusakan, warga Jakarta yang tinggal di gedung bertingkat dan apartemen merasakan guncangan yang lebih kuat. Terhitung terjadi beberapa kali Jakarta dan sekitarnya diguncang oleh gempa. Hal ini menunjukkan bahwa bencana yang sama bisa berulang di Jakarta dan sekitarnya karena fakta membuktikan bahwa sejarah gempa selalu terulang dalam periode waktu tertentu. Oleh karena itu, bangunan - bangunan tinggi di Jakarta dan sekitarnya harus dibangun dengan konstruksi tahan gempa untuk mencegah terjadi kegagalan struktur sehingga diharapkan dapat meminimalisir kerusakan yang terjadi dan korban jiwa akibat gempa yang terjadi.

Dalam perencanaan konstruksi bangunan tahan gempa, material dan sistem struktur merupakan hal utama yang perlu diperhatikan. Penggunaan material baja komposit pada struktur bangunan dapat menjadi solusi dalam perencanaan konstruksi bangunan tahan gempa dikarenakan material baja memiliki beberapa keunggulan dibandingkan material lain seperti memeliki sifat daktilitas dan kekuatan yang tinggi. Adanya interaksi antara komponen struktur baja dan beton dengan karakteristik dasar bahan yang dioptimalkan membuat penggunaan baja komposit akan memanfaatkan seluruh penampang untuk menerima beban sehingga dengan penampang yang lebih kecil, beban yang mampu diterima sama dengan beton bertulang biasa.

Beberapa keunggulan sistem komposit antara lain, penghematan berat baja, penampang balok yang digunakan lebih kecil, kekakuan lantai meningkat, dan kapasitas menahan beban lebih besar [1].

Selain dari segi material, dari segi sistem struktur perlu diperhatikan. Pemilihan sistem penahan gempa yang tepat akan mempengaruhi kinerja dari bangunan dalam menahan beban gempa. Sistem Rangka Bresing Konsentris Khusus (SRBKK) adalah sebuah sistem yang memiliki keunggulan antara lain, membuat elemen struktur menjadi lebih kaku dan dari segi pemasangan, dan perbaikan kerusakan struktur SRBKK lebih mudah. Hal ini perlu diperhatikan karena dalam mendesain bangunan tahan gempa, kita tidak hanya melihat dari segi perencanaan saja, tapi juga pemasangan dan perbaikan kerusakan struktur perlu diperhatikan.

Dengan meninjau beberapa hal diatas, maka pada studi ini akan dilakukan perencanaan modifikasi pada gedung Apartemen Grandhika City Jatiwarna Bekasi - Tower Emerald yang terletak pada daerah rawan gempa. Bangunan setinggi 22 lantai ini akan dimodifikasi dengan menggunakan baja komposit dan Sistem Rangka Bresing konsentris Khusus (SRBKK) untuk mendapatkan kinerja struktur yang lebih baik dan lebih efektif dalam meningkatkan kapasitas pembebanan serta kekakuan bangunan.

\section{TINJAUAN PUSTAKA}

Sistem struktur CBF merupakan salah satu sistem struktur yang digunakan untuk menahan beban lateral dengan kekakuan struktur yang tinggi. Kekakuan yang tinggi pada struktur ini dihasilkan oleh elemen batang diagonal yang berfungsi untuk menahan beban lateral pada struktur. Pada 
sistem struktur ini, elemen bracing diharapkan mampu berdeformasi inelastic yang besar tanpa terjadi kehilangan yang signifikan pada kekuatan dan kekakuan struktur. Secara umum, sistem struktur CBF memiliki kekakuan yang lebih tinggi dibandingkan dengan struktur MRF, karena adanya elemen bresing pada struktur. Namun demikian, kekakuan yang besar pada CBF mengakibatkan deformasi yang terjadi pada struktur lebih terbatas sehingga daktilitas struktur CBF lebih rendah jika dibandingkan dengan sistem struktur MRF [2].

Pada sistem struktur CBF, dibagi menjadi dua kategori yaitu Sistem Rangka Bresing Konsentrik Biasa (SRBKB) dan Sistem Rangka Bresing Konsentrik Khusus (SRBKK). Pada sistem SRBKB diharapkan sistem ini dapat mengalami deformasi inelastic secara terbatas apabila dibebani oleh gaya-gaya yang berasal dari beban gempa rencana. Berbeda dengan SRBKB, pada sistem SRBKK diharapkan struktur dapat berdeformasi inelastic cukup besar akibat gaya gempa rencana. Sistem Sistem SRBKK memiliki daktilitas yang lebih tinggi dibandingkan SRBKB dan penurunan kekuatan pada SRBKK
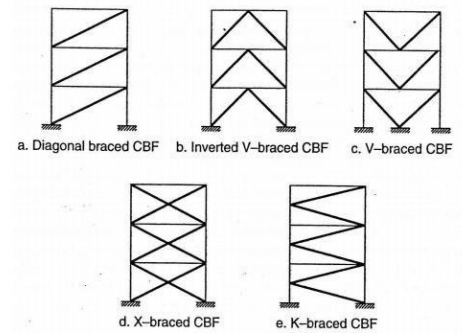

Gambar 1. Konfigurasi Bresing CBF.
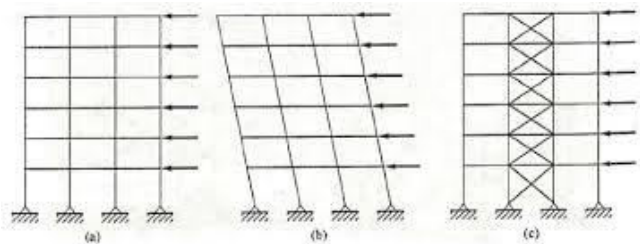

Gambar 2. Kekakuan Sistem Rangka Bresing Khusus.

\section{METODOLOGI}

Urutan penyelesaian Studi ini dapat dilihat pada bagan alir dibawah ini:

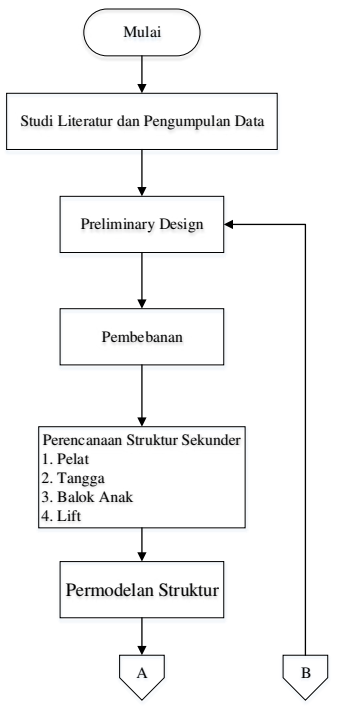

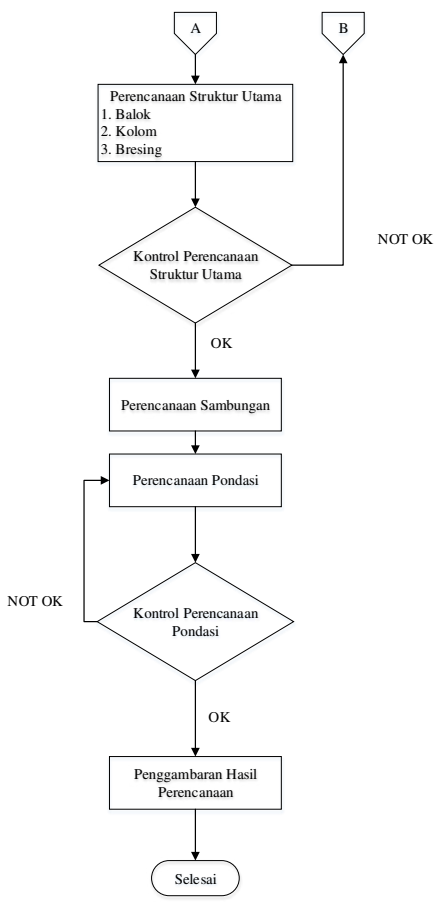

Gambar 3. Diagram Alir Penyelesaian Studi.

Direncanakan sebuah gedung perkantoran 26 lantai dengan data- data sebagai berikut:

- Nama Gedung : Apartemen Grandhika City Jatiwarna

Bekasi - Tower Emerald

- Lokasi Rencana : Bekasi

- Fungsi : Gedung Apartemen

- Struktur Utama : Baja

- Sistem Struktur : Sistem Rangka Bresing Konsentris Khusus

- Jumlah Lantai : 22 lantai

- Rencana Pondasi : Tiang Pancang

Data material:

- Profil kolom : Profil HSS (BJ41)

- Profil balok : Profil WF (BJ41)

- Profil bracing : Profil WF (BJ41)

\section{PERENCANAAN STRUKTUR SEKUNDER}

\section{A. Pelat Atap dan Pelat Lantai}

Pelat lantai atap dan lantai perkantoran direncanakan menggunakan bondek dari Super Floor Deck dengan tebal $0,75 \mathrm{~mm}$. Hasil perhitungan struktur pelat ini tersaji pada tabel 1 .

Tabel 1.

Dimensi dan Penulangan Pelat Atap

\begin{tabular}{cccc}
\hline \hline Tipe Pelat & Bentang & Tebal Pelat & Tulangan Negatif \\
\hline 1 & $3,750 \mathrm{~m}$ & $11 \mathrm{~cm}$ & $\emptyset 10-300$ \\
2 & $3,325 \mathrm{~m}$ & $11 \mathrm{~cm}$ & $\emptyset 10-300$ \\
3 & $2,800 \mathrm{~m}$ & $9 \mathrm{~cm}$ & $\emptyset 10-300$ \\
\hline \hline
\end{tabular}

Tabel 2.

Dimensi dan Penulangan Pelat Lantai

\begin{tabular}{cccc}
\hline \hline Tipe Pelat & Bentang & Tebal Pelat & Tulangan Negatif \\
\hline 1 & $3,750 \mathrm{~m}$ & $11 \mathrm{~cm}$ & $\emptyset 10-150$ \\
2 & $3,325 \mathrm{~m}$ & $11 \mathrm{~cm}$ & $\emptyset 10-200$ \\
3 & $2,800 \mathrm{~m}$ & $9 \mathrm{~cm}$ & $\emptyset 10-250$ \\
\hline \hline
\end{tabular}




\section{B. Perencanaan Balok Anak}

Fungsi dari balok sekunder adalah menerima beban dari pelat lantai lalu meneruskan serta membagi beban yang dipikul ke balok utama. Balok sekunder direncanakan menggunakan wide flange (WF) BJ-41. Hasil perhitungan balok sekunder tersaji pada tabel 3 .

Tabel 3.

Dimensi Balok Anak Atap

\begin{tabular}{ccclllllllll}
\hline \hline $\begin{array}{c}\text { Balok } \\
\text { anak } \\
\text { Lantai }\end{array}$ & $\begin{array}{c}\text { Panjang } \\
\text { balok } \\
\text { anak (m) }\end{array}$ & $\begin{array}{c}\text { Jarak antar } \\
\text { balok anak } \\
(\mathrm{m})\end{array}$ & \multicolumn{1}{l}{ Profil yang digunakan } & \\
\hline 1 & 3,325 & 2,8 & 200 & x & 100 & x & 4,5 & x & 7 \\
2 & 3,325 & 3,75 & 200 & x & 100 & x & 4,5 & x & 7 \\
3 & 5,6 & 2,8 & 250 & x & 125 & x & 6 & x & 9 \\
4 & 5,6 & 3,75 & 300 & x & 150 & x & 5,5 & x & 8 \\
5 & 7,5 & 2,8 & 350 & x & 175 & x & 6 & x & 9 \\
\hline \hline
\end{tabular}

Tabel 4.

Dimensi Balok Anak Lanta

\begin{tabular}{cccccccccc}
\hline \multicolumn{1}{c}{$\begin{array}{c}\text { Balok } \\
\text { anak } \\
\begin{array}{c}\text { Lanta } \\
\text { i }\end{array}\end{array}$} & $\begin{array}{c}\text { Panjang } \\
\text { balok } \\
\text { anak (m) }\end{array}$ & $\begin{array}{c}\text { Jarak antar } \\
\text { balok anak } \\
(\mathrm{m})\end{array}$ & \multicolumn{1}{c}{ Profil yang digunakan } \\
\hline 1 & 3,325 & 2,8 & 200 & x & 100 & x & 5,5 & x & 8 \\
2 & 3,325 & 3,75 & 200 & x & 100 & x & 5,5 & x & 8 \\
3 & 5,6 & 2,8 & 300 & x & 150 & x & 6,5 & x & 9 \\
4 & 5,6 & 3,75 & 350 & x & 175 & x & 6 & x & 9 \\
5 & 7,5 & 2,8 & 400 & x & 200 & x & 8 & x & 13 \\
6 & 7,5 & 3,75 & 400 & x & 200 & x & 8 & x & 13 \\
\hline \hline
\end{tabular}

\section{Perencanaan Tangga dan Bordes}

Tangga adalah sebuah konstruksi yang dirancang untuk menghubungi dua tingkat vertikal yang memiliki jarak satu sama lain.

Data Teknis Perencanaan Tangga

$\begin{array}{ll}\text { - } \text { Mutu baja } & =\mathrm{BJ}-41 \\ \text { - } \text { Tinggi antar lantai } & =500 \mathrm{~cm} \\ \text { - } \text { Tinggi bordes } & =250 \mathrm{~cm} \\ \text { - Panjang tangga } & =392 \mathrm{~cm} \\ \text { - Lebar tangga } & =145 \mathrm{~cm} \\ \text { - Lebar bordes } & =190 \mathrm{~cm} \\ \text { - Lebar injakan (i) } & =28 \mathrm{~cm} \\ \text { - Lebar pegangan tangga } & =10 \mathrm{~cm}\end{array}$

Tabel 5.

Dimensi Pelat Tangga

\begin{tabular}{cccccc}
\hline \hline \multirow{3}{*}{ Elemen Pelat } & $\begin{array}{c}\text { Beban } \\
\text { Berguna } \\
\left(\mathrm{kg} / \mathrm{m}^{2}\right)\end{array}$ & $\begin{array}{c}\text { Bentang } \\
(\mathrm{m})\end{array}$ & $\begin{array}{c}\text { Tebal } \\
\text { Pelat } \\
(\mathrm{cm})\end{array}$ & $\begin{array}{c}\text { Tulangan } \\
\text { Negatif } \\
\left(\mathrm{cm}^{2} / \mathrm{m}\right)\end{array}$ & $\begin{array}{c}\text { Tulangan } \\
\text { susut }\end{array}$ \\
\hline
\end{tabular}

\begin{tabular}{|c|c|c|c|c|c|c|}
\hline $\begin{array}{c}\text { Pelat anak } \\
\text { tangga } \\
\text { Bordes } \\
\end{array}$ & $\begin{array}{l}1000 \\
600 \\
\end{array}$ & $\begin{array}{l}1,5 \\
2\end{array}$ & $\begin{array}{l}9 \\
9 \\
\end{array}$ & 2,0 & & $\begin{array}{c}\text { Wire Mesh } \\
\mathrm{d}=5 \mathrm{~mm}\end{array}$ \\
\hline \multicolumn{7}{|c|}{$\begin{array}{c}\text { Tabel } 6 . \\
\text { Dimensi Balok Tangga }\end{array}$} \\
\hline \multirow{2}{*}{ Elemen } & \multirow{2}{*}{\multicolumn{2}{|c|}{ Jenis Profil/Bahan }} & \multicolumn{2}{|c|}{$\mathrm{Mu}(\mathrm{kg} . \mathrm{m})$} & \multicolumn{2}{|c|}{ Lendutan } \\
\hline & & & $\mathrm{Mu}$ & $\varnothing \mathrm{Mn}$ & $\mathrm{f}$ ijin & $f \max$ \\
\hline $\begin{array}{c}\text { Balok Utama } \\
\text { Tangga } \\
\text { Balok }\end{array}$ & WF250. & & 4161,151 & 6863 & 1,84 & 0,564 \\
\hline $\begin{array}{l}\text { Penumpu } \\
\text { Tangga }\end{array}$ & WF250. & & 3875,877 & 6862,5 & 1,04 & 0,21 \\
\hline
\end{tabular}

\section{KONTROL HASIL ANALISIS STRUKTUR}

\section{A. Kontrol Partisipasi Massa}

Partisipasi massa harus menyertakan jumlah ragam terkombinasi minimal $90 \%$ dari massa aktual yang berasal dari masing-masing arah horizontal dan orthogonal yang ditinjau [3].

Tabel 6.

Kontrol Nilai Partisipasi Massa

\begin{tabular}{lrrrrr}
\hline \hline Case & Mode & Period $(\mathrm{sec})$ & Sum UX & Sum UY & Sum UZ \\
\hline Modal & 1 & 2.174 & $4.01 \mathrm{E}-05$ & 0.7847 & 0 \\
Modal & 2 & 1.887 & 0.7625 & 0.7847 & 0 \\
Modal & 3 & 1.736 & 0.7895 & 0.7847 & 0 \\
Modal & 4 & 0.712 & 0.7895 & 0.8998 & 0 \\
Modal & 5 & 0.608 & 0.9034 & 0.8998 & 0 \\
Modal & 6 & 0.558 & 0.9051 & 0.8998 & 0 \\
Modal & 7 & 0.402 & 0.9051 & 0.9293 & 0 \\
Modal & 8 & 0.366 & 0.9051 & 0.9294 & 0 \\
Modal & 9 & 0.332 & 0.9366 & 0.9294 & 0 \\
Modal & 10 & 0.303 & 0.9369 & 0.9295 & 0 \\
Modal & 11 & 0.303 & 0.9369 & 0.9327 & 0 \\
Modal & 12 & 0.275 & 0.9369 & 0.945 & 0 \\
\hline \hline
\end{tabular}

B. Kontrol Waktu Getar Alami Fundamental

Perkiraan periode alami fundamental (Ta) dalam detik, harus ditentukan dengan persamaan berikut:

$\mathrm{Ta}=\mathrm{Ct} . \mathrm{hn}^{\mathrm{x}} ; \mathrm{Ct}=0,0731 ; \mathrm{x}=0,75 ; \mathrm{hn}=70,2 \mathrm{~m}$

$\mathrm{Ta}=0,0731 \cdot 70,2^{0,75}=1,773$ detik

Dengan nilai $\mathrm{SD} 1=0,356$, maka $\mathrm{Cu}=1,4$

Sehingga periode sruktur yang diijinkan adalah :

$\mathrm{T}=\mathrm{Ta} . \mathrm{Cu}=1,773.1,4=2,482$ detik

Tabel 7.

Kontrol Waktu Getar Alami Fundamental

\begin{tabular}{crrr}
\hline \hline Case & Mode & Period $(\mathrm{sec})$ & Frequency $(\mathrm{cyc} / \mathrm{sec})$ \\
\hline Modal & 1 & 2.174 & 0.46 \\
Modal & 2 & 1.887 & 0.53 \\
Modal & 3 & 1.736 & 0.576 \\
Modal & 4 & 0.712 & 1.404 \\
Modal & 5 & 0.608 & 1.645 \\
Modal & 6 & 0.558 & 1.794 \\
Modal & 7 & 0.402 & 2.485 \\
Modal & 8 & 0.366 & 2.729 \\
Modal & 9 & 0.332 & 3.011 \\
Modal & 10 & 0.303 & 3.298 \\
Modal & 11 & 0.303 & 3.301 \\
Modal & 12 & 0.275 & 3.636 \\
\hline \hline
\end{tabular}

Dari tabel diatas $\mathrm{Tc}=2,174 \mathrm{~s}$, maka berdasarkan kontrol aktu getar alami fundamental, nilai $\mathrm{T}$ masih lebih kecil dari $\mathrm{Cu}$.T. Jadi analisis struktur memenuhi syarat [3].

\section{Kontrol Nilai Akhir Respon Spektrum}

Kombinasi respons untuk gaya geser dasar ragam dinamik (Vt) harus lebih besar $85 \%$ dari gaya geser dasar statik (V) atau $\left(\mathrm{V}_{\text {dinamik }} \geq 0,85 \mathrm{~V}_{\text {statik }}\right)$ [3].

Kontrol nilai akhir respon spectrum:

- Arah-x :

$\mathrm{V}_{\text {dinamik }} \geq 0,85$. $\mathrm{V}_{\text {statik }}$

$3044927.02 \mathrm{~kg}>0,85.631816,1 \mathrm{~kg}$

$3044927.02 \mathrm{~kg}>537043.7 \mathrm{~kg} \quad(\mathrm{OK})$ 
- Arah-y :

$\mathrm{V}_{\text {dinamik }} \geq 0,85$. $\mathrm{V}_{\text {statik }}$

$3068412.31 \mathrm{~kg}>0,85.631816,1 \mathrm{~kg}$

$3068412.31 \mathrm{~kg}>537043.7 \mathrm{~kg} \quad(\mathrm{OK})$

\section{Kontrol Simpangan (Drift)}

Gempa menyebabkan struktur bertingkat rawan terhadap terjadinya simpangan horizontal (Drift). Dan apabila simpangan horizontal ini melebihi syarat aman yang telah ditentukan maka gedung akan mengalami keruntuhan [3].

Tabel 8.

Kontrol Simpangan Arah sumbu X

\begin{tabular}{ccccccc}
\multicolumn{7}{c}{ Kontrol Simpangan Arah sumbu X } \\
Lantai & hi & $\Delta \mathrm{xe}$ & $\Delta \mathrm{x}$ & $\Delta \mathrm{a}$ & $\Delta \mathrm{a} / \rho$ & $\Delta \leq \Delta \mathrm{a} / \rho$ \\
& & $(\mathrm{mm})$ & $(\mathrm{mm})$ & $(\mathrm{mm})$ & $(\mathrm{mm})$ & $(\mathrm{mm})$ \\
\hline Lantai 22 & 3300 & 5.3328 & 26.664 & 66 & 66 & OK \\
Lantai 21 & 3000 & 5.295 & 26.475 & 60 & 60 & OK \\
Lantai 20 & 3000 & 5.778 & 28.89 & 60 & 60 & OK \\
Lantai 19 & 3000 & 6.324 & 31.62 & 60 & 60 & OK \\
Lantai 18 & 3000 & 6.918 & 34.59 & 60 & 60 & OK \\
Lantai 17 & 3000 & 7.524 & 37.62 & 60 & 60 & OK \\
Lantai 16 & 3000 & 8.115 & 40.575 & 60 & 60 & OK \\
Lantai 15 & 3000 & 8.709 & 43.545 & 60 & 60 & OK \\
Lantai 14 & 3000 & 9.132 & 45.66 & 60 & 60 & OK \\
Lantai 13 & 3000 & 9.597 & 47.985 & 60 & 60 & OK \\
Lantai 12 & 3000 & 10.029 & 50.145 & 60 & 60 & OK \\
Lantai 11 & 3000 & 10.437 & 52.185 & 60 & 60 & OK \\
Lantai 10 & 3200 & 11.6032 & 58.016 & 64 & 64 & OK \\
Lantai 9 & 3200 & 11.8368 & 59.184 & 64 & 64 & OK \\
Lantai 8 & 3000 & 11.091 & 55.455 & 60 & 60 & OK \\
Lantai 7 & 3000 & 11.025 & 55.125 & 60 & 60 & OK \\
Lantai 6 & 3000 & 11.055 & 55.275 & 60 & 60 & OK \\
Lantai 5 & 3000 & 11.094 & 55.47 & 60 & 60 & OK \\
Lantai 4 & 3000 & 11.46 & 57.3 & 60 & 60 & OK \\
Lantai 3 & 5000 & 18.7425 & 93.7125 & 100 & 100 & OK \\
Lantai 2 & 3500 & 12.3445 & 61.7225 & 70 & 70 & OK \\
Lantai 1 & 4000 & 8.212 & 41.06 & 80 & 80 & OK \\
Lantai 0 & 0 & 0 & 0 & 0 & 0 & OK \\
\hline \hline
\end{tabular}

\section{PERHITUNGAN STRUKTUR PRIMER}

\section{A. Bressing}

Bressing direncanakan menggunakan profil WF $600 \times 300$ x 12 x 20. Berdasarkan SNI 03-1729-2002 Pasal 15.13.6.1, kuat kombinasi- aksial- dan lentur perlu pada batang bresing harus sebesar 1,25 Ry Vn.

Bressing tarik

$\phi N_{n}=0,90 \times f y \times \mathrm{Ag}$

$=0,9 \times 2500 \times 192,5=433125 \mathrm{~kg}$

$\phi . N_{n}=433125 \mathrm{~kg}>\mathrm{Pu}=249438,5 \mathrm{~kg}(\mathrm{OK})$

Bresing tekan

$\phi . N_{n}=0,85 \times A g \times \frac{f y}{\omega}$

$\phi . N_{n}=0,85 \times 192,5 \times \frac{2500}{1,57}=260893,3 \mathrm{~kg}$

$\phi . N_{n}=260893,3 \mathrm{~kg}>\mathrm{Pu}=259192,14 \mathrm{~kg}(O K)$

\section{B. Balok}

Balok direncanakan menggunakan profil WF 500 x 300 x $11 \times 15$ dan WF 450 × $200 \times 9 \times 14$. Dari output ETABS diperoleh gaya dalam yang dipakai dalam desain adalah:

Kontrol balok WF 500x300x11x15

$$
\begin{array}{ll}
\mathrm{Mu} & =-49564,896 \mathrm{~kg} \cdot \mathrm{m} \leq \varnothing \mathrm{Mn}=59917,5 \mathrm{~kg} \cdot \mathrm{m} \\
\mathrm{Vu} & =37869,96 \mathrm{~kg} \geq \varnothing \mathrm{Vn}=59400 \mathrm{~kg} \\
\mathrm{f}^{0} & =0,277 \mathrm{~cm} \leq \mathrm{f} \mathrm{ijin}=2,083 \mathrm{~cm}
\end{array}
$$

\section{Kolom}

Perhitungan kolom dihitung sceara komposit. Kolom direncanakan menggunakan profil CFT $600 \times 600 \times 32 \times 32$, HSS $550 \times 550 \times 22 \times 22$, dan CFT $500 \times 500 \times 22 \times 22$, dengan kontrol kuat nominal penampang sebagai berikut: Rumus Interaksi untuk kolom CFT 600 x 600 x 32 x 32:

$\frac{P r}{\varphi P n}=0,596>0,2 \rightarrow$ Interaksi 2

$$
\begin{gathered}
\text { Kontrol Interaksi "Balok - Kolom" } \\
\frac{P_{u}}{\emptyset P_{n}} \geq 0,2 \rightarrow \frac{P_{u}}{\emptyset P_{n}}+\frac{8}{9}\left(\frac{M_{u x}}{\emptyset_{b} M_{n x}}+\frac{M_{u y}}{\emptyset_{b} M_{n y}}\right) \leq 1,0 \\
0,967 \leq 1,0(\mathrm{OK})
\end{gathered}
$$

\begin{tabular}{|c|c|c|}
\hline \multicolumn{2}{|l|}{ Elemen } & Dimensi \\
\hline \multicolumn{2}{|c|}{ Bressing arah $\mathrm{X}$} & WF $600 \times 300 \times 12 \times 20$ \\
\hline \multicolumn{2}{|c|}{ Bressing arah $\mathrm{Y}$} & WF $600 \times 300 \times 12 \times 20$ \\
\hline \multirow{3}{*}{ Balok Lantai } & $7,5 \mathrm{~m}$ & WF $500 \times 300 \times 11 \times 15$ \\
\hline & $5,6 \mathrm{~m}$ & WF $500 \times 300 \times 11 \times 15$ \\
\hline & $3,325 \mathrm{~m}$ & WF $450 \times 200 \times 9 \times 14$ \\
\hline \multirow{3}{*}{ Balok Atap } & $7,5 \mathrm{~m}$ & WF $500 \times 300 \times 11 \times 15$ \\
\hline & $5,6 \mathrm{~m}$ & WF $500 \times 300 \times 11 \times 15$ \\
\hline & $3,325 \mathrm{~m}$ & WF $450 \times 200 \times 9 \times 14$ \\
\hline \multicolumn{2}{|l|}{ Kolom Lt 1-7 } & CFT $600 \times 600 \times 32 \times 32$ \\
\hline \multicolumn{2}{|c|}{ Kolom Lt 8-15 } & CFT $550 \times 550 \times 22 \times 22$ \\
\hline \multicolumn{2}{|c|}{ Kolom Lt 15-22 } & CFT $500 \times 500 \times 22 \times 22$ \\
\hline
\end{tabular}

Hasil seluruh perhitungan struktur primer akan disajikan pada tabel 9 .

Tabel 9.

Hasil Perhitugan Primer

VII. PERENCANAAN SAMBUNGAN

A. Sambungan Struktur Sekunder

Tabel 10.

Sambungan Struktur Sekunder

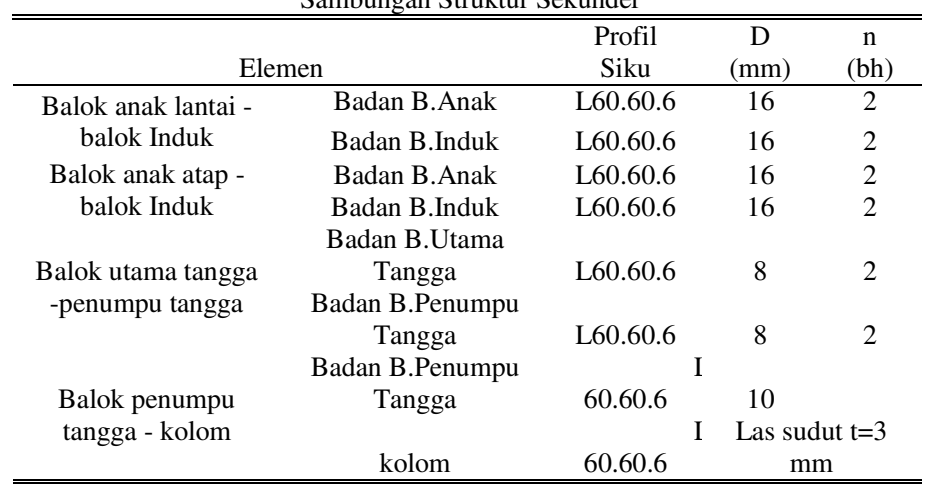

Pada perencanaan sambungan, direncanakan baut dengan mutu A325 dan pelat penyambung profil siku dengan mutu BJ41.Baut direncanakan hanya memikul beban geser yang berasal dari struktur sekunder. Perhitungan sambungan dianggap sebagai sendi. Hasil perhitungan sambngan struktur sekunder tersaji pada Tabel 10. 


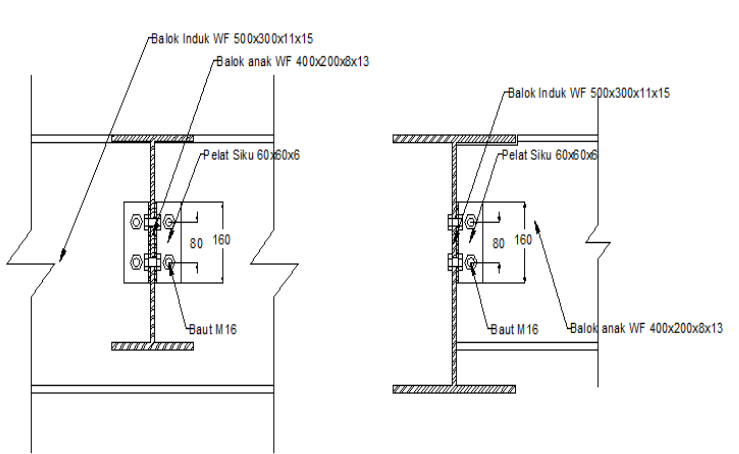

Gambar 4. Sambungan Balok Anak dan Balok Induk.

\section{B. Sambungan Struktur Primer}

Pada perencanaan sambungan, direncanakan baut dengan mutu A325, Mutu las $\mathrm{FE}_{70 \mathrm{xx}}$ dan $\mathrm{FE}_{110 \mathrm{xx}}$, dan pelat penyambung mutu BJ-41. Sambungan pada struktur primer direncanakan dengan sambungan kaku (rigid connection) dimana sambungan memikul beban geser Pu dan momen $\mathrm{Mu}$.

Hasil perhitungan sambungan struktur primer tersaji pada tabel 11.

Tabel 11.

Sambungan Struktur Primer

\begin{tabular}{|c|c|c|c|c|}
\hline Elemen & "Jenis Profil & $\overline{\mathrm{D}(\mathrm{mm})}$ & $\begin{array}{c}\mathrm{N} \\
\text { (buah) }\end{array}$ & $\begin{array}{l}\text { Las } \\
(\mathrm{mm})\end{array}$ \\
\hline 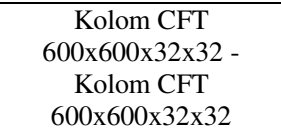 & $\begin{array}{c}\text { Pelat t.50 } \\
\mathrm{mm}\end{array}$ & - & - & 30 \\
\hline $\begin{array}{c}\text { Balok induk lantai - } \\
\text { kolom (badan balok) } \\
\text { (A325) }\end{array}$ & $\begin{array}{c}\text { Single } \\
\text { Plate } \mathrm{t}=14\end{array}$ & 24 & 4 & - \\
\hline $\begin{array}{l}\text { Balok induk lantai }- \\
\text { kolom }(\text { Kolom })\left(\mathrm{Fe}_{110 \mathrm{xx}}\right)\end{array}$ & $\begin{array}{c}\text { Single } \\
\text { Plate } t=14\end{array}$ & - & - & 6 \\
\hline $\begin{array}{l}\text { Balok induk lantai - } \\
\text { kolom (Sayap Balok } \\
\text { Induk) (Baut A325) }\end{array}$ & $\begin{array}{c}\text { Single } \\
\text { Plate } \mathrm{t}=16\end{array}$ & 30 & 10 & - \\
\hline Kolom - Base Plate & $\begin{array}{l}\text { Continental } \\
\text { Steel }\end{array}$ & 30 & 16 & 45 \\
\hline $\begin{array}{c}\text { Bresing WF } \\
600 \times 300 \times 11 \times 15\end{array}$ & Pelat $\mathrm{t}=20$ & 24 & 10 & 10 \\
\hline
\end{tabular}

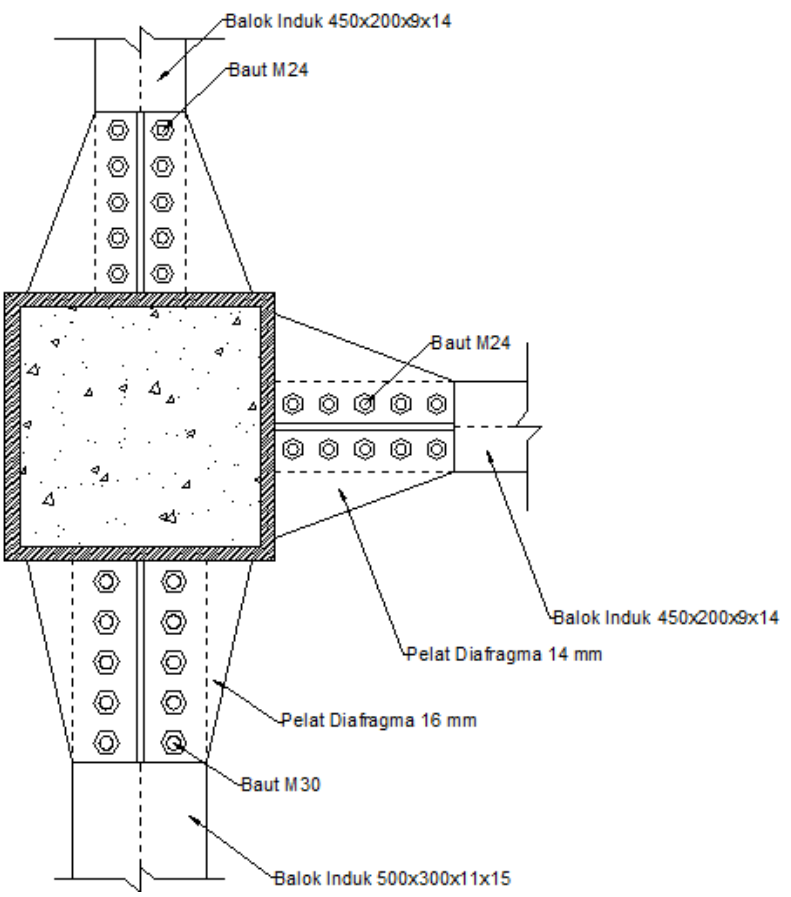

Gambar 5. Sambungan Kolom dan Balok Induk.

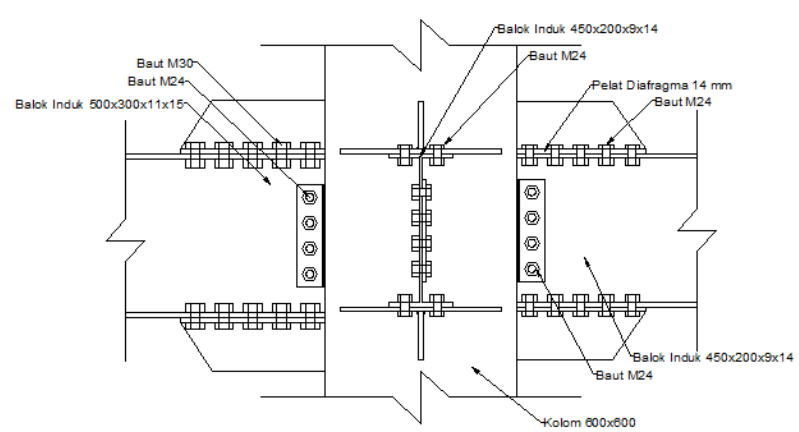

Gambar 6. Sambungan Kolom dan Balok Induk.

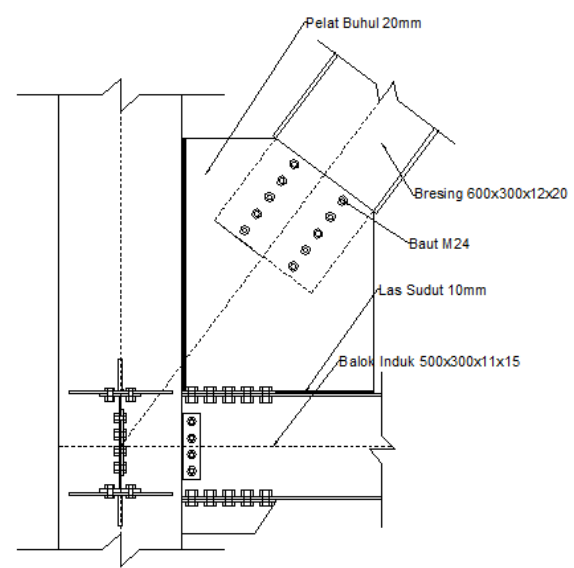

Gambar 7. Sambungan Bresing

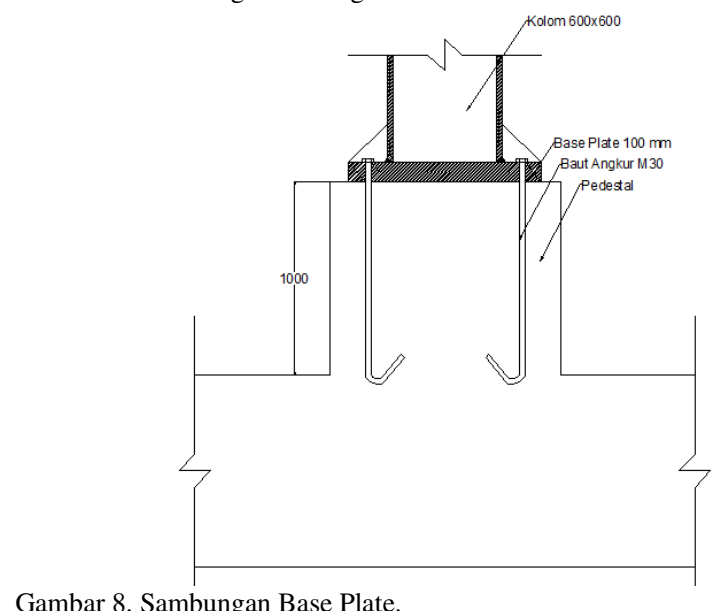

\section{PERHITUNGAN STRUKTUR BAWAH}

\section{A. Pondasi Tiang Pancang}

Pondasi yang digunakan pada perencanaan gedung perkantoran berasal dari tiang pancang beton (Concrete Pile) dengan penampang bulat berongga (Round Hollow) dari produk dari PT. WIKA Beton dengan spesifikasi adalah sebagai berikut:

- Diameter tiang $\quad: 600 \mathrm{~mm}$

- Tebal tiang : $100 \mathrm{~mm}$

- Klasifikasi :A1

- Concrete cross section : $1571 \mathrm{~cm} 2$

- Berat : $409 \mathrm{~kg} / \mathrm{m}$

- Bending moment crack : 19,3 tm

- Bending momen ultimate: 22,7 tm

- Allowable axial load : 252,7 t

Daya dukung ijin dari satu tiang pancang yang berdiri sendiri adalah: 


$$
\begin{aligned}
& P_{\text {ijin 1 tiang }}=\frac{Q u}{S F}=\frac{709,372}{3}=236,46 \text { ton } \\
& \text { Kontrol beban } \\
& \operatorname{Pv}=\frac{V}{n}+\frac{M_{x} y}{\sum y^{2}}+\frac{M_{y} x}{\sum x^{2}}=227030 \mathrm{~kg} \\
& \mathrm{P}_{\max }=227,03 \text { ton }<\mathrm{Q}_{\mathrm{ijin}}=236,46 \text { ton }(\mathrm{OK}) \\
& \text { Hasil perhitungan kebutuhuan tiang pancang dapat dilihat } \\
& \text { pada tabel berikut ini: }
\end{aligned}
$$

\begin{tabular}{|c|c|c|c|c|c|c|c|}
\hline $\begin{array}{c}\text { Jenis } \\
\text { Pilecap }\end{array}$ & $\begin{array}{l}\text { Dimensi } \\
(\mathrm{cm})\end{array}$ & $\begin{array}{c}\text { Diamete } \\
\text { Tiang } \\
(\mathrm{cm})\end{array}$ & \multicolumn{2}{|c|}{$\begin{array}{l}\text { Kedalaman } \\
\text { Tiang } \\
\text { Pancang } \\
\text { (m) }\end{array}$} & $\begin{array}{l}\text { Jarak } \\
\text { Antar } \\
\text { Tiang } \\
(\mathrm{cm})\end{array}$ & $\begin{array}{c}\text { Jarak } \\
\text { Tiang } \\
\text { ke } \\
\text { Tepi } \\
(\mathrm{cm})\end{array}$ & $\begin{array}{l}\text { Konfigu } \\
\text { si Tian }\end{array}$ \\
\hline Pilecap & $1440 \times 360$ & \multirow{2}{*}{\multicolumn{2}{|c|}{60}} & \multirow[b]{2}{*}{22} & \multirow{3}{*}{180} & \multirow{3}{*}{90} & \multirow{3}{*}{8} \\
\hline 1 & $\mathrm{x} 150$ & & & & & & \\
\hline Pilecap & $720 x 720 x$ & & & & & & \\
\hline 2 & 150 & \multicolumn{2}{|c|}{60} & 22 & \multirow[t]{2}{*}{180} & \multirow[t]{2}{*}{90} & \multirow[t]{2}{*}{4} \\
\hline Pilecap & $540 x 360 x$ & & & \multirow[b]{2}{*}{18} & & & \\
\hline 3 & 150 & \multicolumn{2}{|c|}{60} & & \multirow[t]{2}{*}{180} & \multirow[t]{2}{*}{90} & \multirow[t]{2}{*}{3} \\
\hline Pilecap & $720 x 540 x$ & & & & & & \\
\hline 4 & 150 & \multicolumn{2}{|c|}{60} & 16 & \multirow[t]{2}{*}{180} & \multirow[t]{2}{*}{90} & \multirow[t]{2}{*}{4} \\
\hline Pilecap & $1080 \times 540$ & \multirow{2}{*}{\multicolumn{2}{|c|}{60}} & \multirow{3}{*}{22} & & & \\
\hline 5 & $\mathrm{x} 150$ & & & & \multirow{2}{*}{180} & 90 & \multirow[t]{2}{*}{6} \\
\hline Pilecap & 180x180x & & & & & & \\
\hline 6 & 150 & 6 & & & 180 & 90 & 1 \\
\hline Pilecap & $720 x 180 x$ & & & & & & \\
\hline 7 & 150 & 6 & & & 180 & 90 & 1 \\
\hline & & Rek & $\begin{array}{r}\mathrm{Ta} \\
\text { itulasi } \mathrm{p}\end{array}$ & . & lecap & & \\
\hline $\begin{array}{l}\text { Jenis } \\
\text { Piisol }\end{array}$ & Dimens & (cm) & $\begin{array}{r}\text { Tulan } \\
\mathrm{Su}\end{array}$ & $\begin{array}{l}\text { Lentur } \\
\mathrm{X}\end{array}$ & & $\begin{array}{r}\text { Tulangar } \\
\text { Suml }\end{array}$ & $\begin{array}{l}\text { entur } \\
Y\end{array}$ \\
\hline & & & Bawah & Atas & & Bawah & Atas \\
\hline Pilecap & $\begin{array}{r}1440 \times 3 \\
0\end{array}$ & $0 x 15$ & $\begin{array}{l}\text { D25 - } \\
170\end{array}$ & $\begin{array}{c}\text { D19- } \\
170\end{array}$ & & $\begin{array}{c}\text { D25 - } \\
190\end{array}$ & $\begin{array}{c}\text { D19 - } \\
190\end{array}$ \\
\hline Pilecap & & & D25 - & D19 - & & D25 - & D19 - \\
\hline 2 & $720 \times 72$ & x150 & 180 & 180 & & 180 & 180 \\
\hline Pilecap & & & D25 - & D19- & & D25 - & D19 - \\
\hline 3 & $540 \times 36$ & x150 & 190 & 190 & & 190 & 190 \\
\hline Pilecap & $700 \times 54$ & $\mathrm{x} 150$ & $\begin{array}{l}\mathrm{D} 25- \\
180\end{array}$ & $\begin{array}{r}\text { D19 - } \\
180\end{array}$ & & $\begin{array}{l}\mathrm{D} 25- \\
190\end{array}$ & $\begin{array}{l}\text { D19 - } \\
190\end{array}$ \\
\hline Pilecap & $1080 \times 5$ & $0 \times 15$ & $\begin{array}{l}100 \\
\mathrm{D} 25-\end{array}$ & D19- & & D25 - & D19 - \\
\hline 5 & 0 & & 180 & 180 & & 190 & 190 \\
\hline $\begin{array}{c}\text { Pilecap } \\
6\end{array}$ & $180 \times 18$ & x150 & $\begin{array}{c}\text { D25 - } \\
180\end{array}$ & $\begin{array}{c}\text { D19 - } \\
180\end{array}$ & & $\begin{array}{c}\text { D25 - } \\
180\end{array}$ & $\begin{array}{c}\text { D19 - } \\
180\end{array}$ \\
\hline Pilecap & & & D25 - & D19 - & & D25 - & D19 - \\
\hline 7 & $720 \times 18$ & $\mathrm{x} 150$ & 180 & 180 & & 190 & 190 \\
\hline
\end{tabular}

Tabel 12.

Rekapitulasi Tiang Pancang

\section{B. Perencanaan Poer}

Untuk penulangan lentur, poer dianalisis sebagai balok kantilever dengan perletakan jepit pada kolom. Dan beban yang bekerja adalah beban terpusat di tiang kolom yang menyebabkan reaksi pada tanah dan berat sendiri poer.

Tulangan tarik yang dibutuhkan untuk pilecap 1 :

- Penulangan Arah X

$$
\begin{aligned}
\text { As } & =\rho \times b \times d_{x} \\
& =0,002 \times 3600 \times 1415,5=10233,71 \mathrm{~mm}^{2}
\end{aligned}
$$

Digunakan tulangan lentur bawah D25-170

$$
\begin{aligned}
& \mathrm{A}_{\mathrm{s}} \quad=\left(\frac{1}{4} \times \pi \times d^{2}\right) \frac{3600}{170} \\
&=10308,3 \mathrm{~mm}^{2}>10233,71 \mathrm{~mm}^{2}(\mathrm{Ok}) \\
&- \text { Penulangan Arah Y } \\
& \text { As }=\rho \times \mathrm{b} \times \mathrm{d}_{\mathrm{y}} \\
&=0,0018 \times 14400 \times 1387,5=35964 \mathrm{~mm}^{2}
\end{aligned}
$$

Digunakan tulangan lentur atas D25-190

$$
\begin{aligned}
\mathrm{A}_{\mathrm{s}} & =\left(\frac{1}{4} \times \pi \times d^{2}\right) \frac{14400}{190} \\
& =36324,4 \mathrm{~mm}^{2}>35964 \mathrm{~mm}^{2}(\mathrm{Ok})
\end{aligned}
$$

Hasil perhitungan kebutuhan tulangan pilecap dapat dilihat pada tabel dibawah ini.

\section{Perencanaan Kolom Pedestal}

Besarnya gaya - gaya dalam kolom diperoleh dari hasil analisis ETABS adalah:

$$
\begin{array}{ll}
\mathrm{Mu} & =157331,5 \mathrm{~kg} \cdot \mathrm{m} \\
\mathrm{Pu} & =1448080 \mathrm{~kg} \\
\mathrm{Vu} & =44111,16 \mathrm{~kg}
\end{array}
$$

Dimensi kolom pedestal $1200 \mathrm{~mm}$ x $1200 \mathrm{~mm}$.

As $=0,0113.1200 .1137=15417,72 \mathrm{~mm}^{2}$

Dipasang tulangan 32D25, As $=16989,733 \mathrm{~mm}^{2}$ Dipasang merata 4 sisi dengan sengkang $\varnothing 10-150$. 4

\section{A. Kesimpulan}

\section{KESIMPULAN DAN SARAN}

Sesuai dengan tujuan penulisan studi ini, maka dapat ditarik kesimpulan sebagai berikut:

Hasil perhitungan pada struktur sekunder telah memenuhi syarat terhadap kontrol kuat penampang, kontrol geser dan lendutan.

Dari kontrol yang dilakukan, kontrol partisipasi massa, kontrol waktu getar alami fundamental, kontrol nilai akhir respon spectrum, kontrol simpangan (drift)) struktur yang direncanakan berada di kota BEkasi memenuhi syarat (analisis struktur dapat digunakan)

Perhitungan pada struktur bawah telah memenuhi persyaratan dimensi dan kontrol akibat pons.

\section{B. Saran}

Diharapkan dengan adanya perencanaan bangunan gedung dengan Sistem Rangka Bresing Konsentris Khusus (SRBKK) ini dapat menjadi inovasi pada perancangan gedung di Indonesia. Selain itu, dapat juga dengan dilakukan studi lebih lanjut mengenai aspek teknis, ekonomis, dan estetika agar perencanaan ini menjadi lebih efektif dan dapat dimodelkan sesuai dengan kondisi sesungguhnya di lapangan.

\section{DAFTAR PUSTAKA}

G. Salmon, Charles, and J. E. Johnson, Struktur Baja desain dan Perilaku Jilid 2 Edisi Kedua. Jakarta: Erlangga, 1991.

[2] A. Abdul, "Studi Perilaku sistem Rangka Baja K-Split EBF (Eccentrically Braced Frames) Terhadap Beban Gempa Dengan Analisis Pushover," 2012.

[3] Badan Standardisasi Nasional, "SNI 1729-2015: Spesifikasi untuk Bangunan Gedung Baja Struktural,” Jakarta, 2015. 